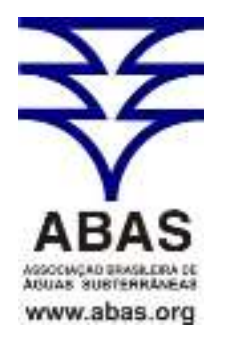

\title{
RELAÇÃO ENTRE O ESCOAMENTO DE BASE E OS DIFERENTES SISTEMAS HIDROGEOLÓGICOS DO ESTADO DE MINAS GERAIS
}

\author{
RELATION BETWEEN THE BASEFLOW AND THE DIFFERENT \\ HYDROGEOLOGICAL SYSTEMS OF THE STATE OF MINAS GERAIS, BRAZIL
}

\author{
Gilberto Coelho ${ }^{1}$; Lucas Machado Pontes ${ }^{2}$; Marcelo Linon Batista ${ }^{3}$; Carlos \\ Rogério de Mello ; Antônio Marciano da Silva ${ }^{5}$
}

Artigo recebido em: 22/10/2014 e aceito para publicação em: 06/11/2015.

DOI: http://dx.doi.org/10.14295/ras.v29i3.27977

\begin{abstract}
Resumo: Estimativas da separação do escoamento superficial em escoamento superficial direto e escoamento de base são importantes para avaliar, entre outros aspectos, a capacidade de manutenção de vazões em períodos de estiagem e a análise das relações entre o escoamento de base e as classes hidrogeológicas pode contribuir para o entendimento dos processos hidrológicos envolvidos. O presente trabalho objetivou estimar o escoamento de base em oito seções de cursos d'água que caracterizam os sistemas hidrogeológicos do Estado de Minas Gerais. Para isto foi utilizado um filtro numérico de modo a avaliar a relação entre sistemas aquíferos e regime de fluxo d'água. Foram utilizados dados diários de vazão, no intervalo de 01/10/1981 a 30/09/1991. Em todos os casos, o escoamento de base foi responsável por mais de $50 \%$ da vazão dos cursos d'água. Os aquíferos compostos por litotipos xistosos, pelíticos e por cobertura detrítica apresentam relação entre o escoamento de base e o escoamento superficial menor do que os demais e, portanto, a mesma classificação estatística. Com base nos resultados apresentados, conclui-se que a hidrogeologia exerce influência indireta na relação entre o escoamento de base e a vazão dos cursos d'água.
\end{abstract}

Palavras-chave: Separação da Hidrógrafa. Hidrogeologia. Filtro Numérico.

\begin{abstract}
The estimation of surface flow into direct surface flow and base flow is fundamental for understanding the hydrologic behavior of basins, being possible, among other features, the capability of discharges maintenance during the dry seasons. Analysis of the related base flow with hydrogeological classes can contribute to understand the hydrological processes involved. This work aimed to estimate the base flow for eight fluviometric stations that were chosen according to the hydro geologic systems observed in the State of Minas Gerais. A numerical filter was employed in order to evaluate the relationship between hydrogeology and water flow regime. Daily discharge data sets, between October/1981 and September/1991, were used in the study. In all cases, the base flow accounted for over $50 \%$ of the water flow in rivers. The hydrogeological systems "xistosa", "pelítica" and "cobertura detrítica" presented smaller amount of base flow in the rivers discharge than other hydrogeological systems and obtained the same statistical classification. Based on the results we concluded that hydrogeology exerts indirect influence on the relationship between the base flow and river discharge.
\end{abstract}

Keywords: Hydrograph separation. Hydrogeology. Numeric filter.

\section{INTRODUÇÃO}

Tradicionalmente a pesquisa e a gestão de recursos hídricos no Brasil têm dado pouca atenção às águas subterrâneas, tratando-a de forma relativamente independente das águas superficiais apesar do fato de que estas são responsáveis pela sua manutenção. Tal incongruência leva a medidas apenas paliativas e parciais no gerenciamento dos recursos hídricos nacionais e, indiretamente, à degradação da qualidade e quantidade da água dos rios, além da superexplotação dos aquíferos (SOPHOCLEOUS, 2007, 2010; SOUZA et al., 2010).

Para promover uma gestão integrada e eficaz é preciso compreender as interações entre as águas superficiais e subterrâneas, considerando estes sistemas como partes de um único recurso.

\footnotetext{
${ }^{1-5}$ Universidade Federal de Lavras - UFLA.(coelho@deg.ufla.br ; lucasmachadopontes@ hotmail.com ; $\underline{\text { marcli- }}$ non@yahoo.com.br ; crmello@deg.ufla.br; marciano@deg.ufla.br )
} 
A interação entre águas subterrânea e superficial ocorre de diversas maneiras, a depender das características físicas de cada bacia hidrográfica, do clima, geomorfologia, hidrografia, das classes de solos e da vegetação. A combinação entre estes fatores determina o nível de água no aquífero freático ao longo da área e o movimento da água no solo (PINDER e CELIA, 2006).

Em regiões de clima úmido, a regularização das vazões nos cursos d'água depende do fluxo de água subterrânea para a superfície, embora haja grande variação da sua participação na vazão (SOPHOCLEOUS, 2002; PARTINGTON et al., 2012). Durante as estações secas, o fluxo de águas nos diversos tipos de mananciais é mantido pelas reservas armazenadas no solo durante a estação chuvosa (água subterrânea). Esse fluxo é denominado escoamento de base (EB) e é caracterizado por apresentar menores variações temporais do que o escoamento superficial.

Com os dados da hidrógrafa de um curso d'água é possível estimar os valores separados para os escoamentos de base e direto (MIRANDA et al., 2014). Diversos métodos são propostos para separar estes componentes do escoamento, dos quais destacam-se os métodos numéricos, como os filtros numéricos digitais (ECKHARDT, 2008). Os filtros numéricos para separação do escoamento de base têm apresentado bons resultados em diversas condições, mesmo os métodos mais simples fornecem respostas consistentes (COMBALICER et al., 2008; LAROCQUE et al., 2010; FAN et al., 2015).

Os filtros numéricos estimam os valores para cada componente, ajustando parâmetros de acordo com as características físicas e hidrológicas da bacia e do curso d'água (COSTA e BACELLAR, 2010). Esta técnica permite obter informações importantes a respeito do comportamento hidrológico nas bacias hidrográficas estudadas, seja para quantificar a recarga do aquífero livre, interpretar dados de qualidade da água, ou calibrar modelos hidrológicos que simulem o escoamento superficial e subterrâneo separadamente, entre outras aplicações (PARTINGTON et al., 2012; SILVA GONZAGA et al., 2010; MATTIUZI et al., 2014; GONZALES et al., 2009).

Porém, os processos de interação da água subterrânea com a superficial ainda são pouco compreendidos, dado sua complexidade e a dificuldade em validar modelos de fluxo da água subterrânea ou na mensuração direta desta (PONTES et al., 2015). Por isso, há a necessidade de estudos para ampliar o conhecimento dos processos de interação supracitados e a hidrogeologia, sobretudo em lugares onde os crescimentos econômicos e populacionais pressionam sobremaneira os recursos naturais, ou em locais onde estes recursos apresentam fragilidade natural (RIBEIRO et al., 2014; MARCUZZO et al., 2014).

O estado de Minas Gerais possui uma grande diversidade de sistemas hidrogeológicos, além de apresentar grande variação climática, topográfica, pedológica e também quanto ao uso e ocupação dos solos (SOUZA, 1995). Desta maneira, é possível analisar o comportamento do escoamento em diferentes situações. Por outro lado, são poucas as informações fluviométricas consistentes disponíveis, o que dificulta o estudo de cada um dos fatores que influenciam no regime de escoamento em bacias hidrográficas.

A partir das considerações anteriores, este trabalho foi realizado, com o objetivo de estimar o escoamento de base em diferentes sistemas aquíferos do estado de Minas Gerais e avaliar a relação entre estes sistemas.

\section{MATERIAL E MÉTODOS}

\subsection{Sistemas hidrogeológicos da área estu- dada}

Segundo Souza (1995), o estado de Minas Gerais possui 10 sistemas hidrogeológicos principais: aluvial, arenítico, basáltico, carbonático, cobertura detrítica, gnáissicogranítico, pelítico, pelítico-carbonático, quartizítico e xistoso (Figura 1). 


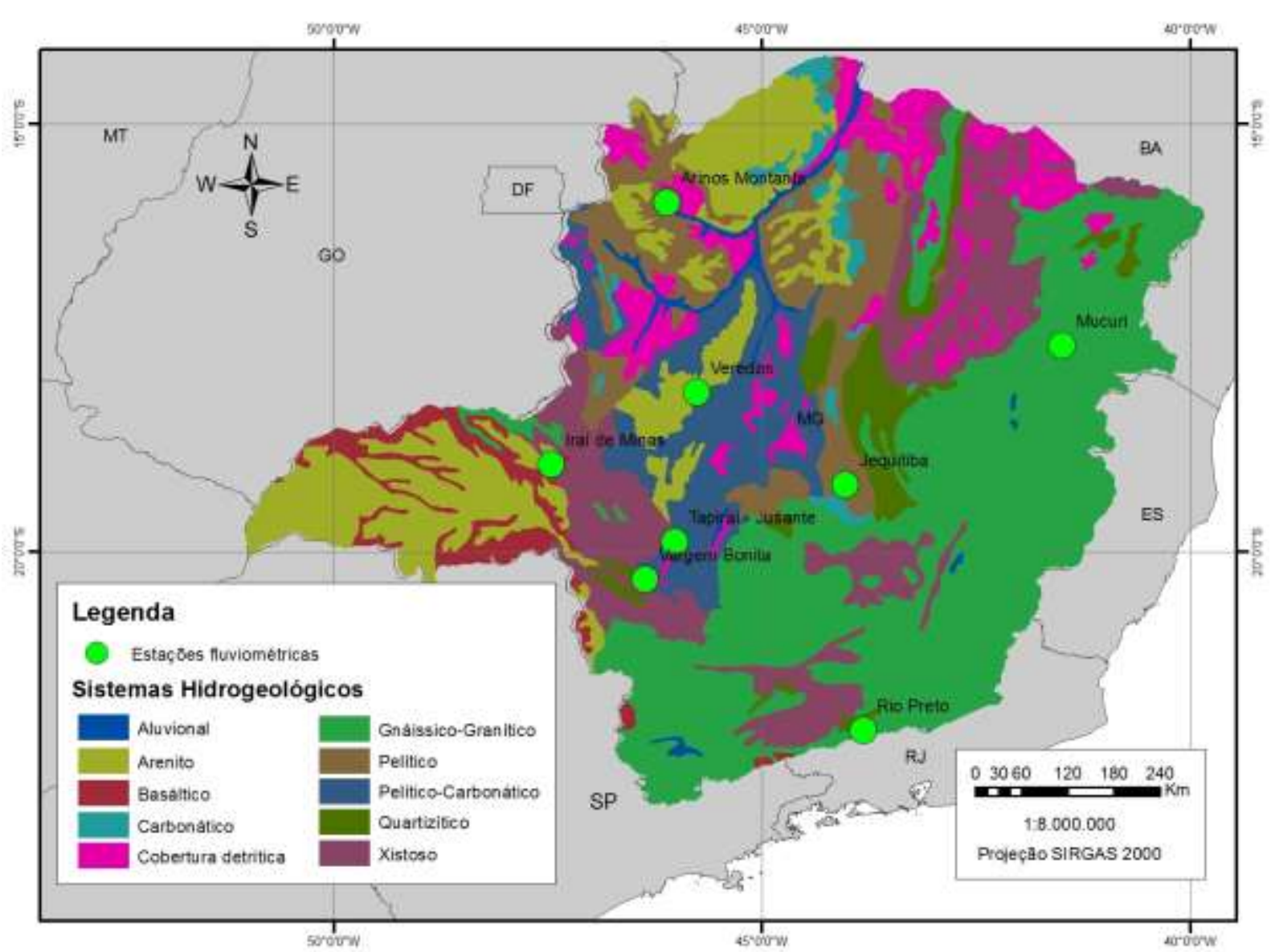

Figura 1- Sistemas hidrogeológicos do Estado de Minas Gerais. Adaptado de Souza, 1995. Escala de origem 1/3.000.000. Datum SIRGAS 2000

Figure - Hydrogeological systems of the State of Minas Gerais. Original scale 1/3.000.000. Adapted from Souza, 1995. Datum SIRGAS 2000

2.2 Estações fluviométricas e séries históricas

Entre as estações fluviométricas existentes em Minas Gerais, foram utilizadas oito estações fluviométricas e oito estações pluviométricas com dados disponibilizados pela Agência Nacional de Águas - ANA (Tabelas 1 e 2) (BRASIL, 2014). Foram usados os dados da série histórica com o período de 01/10/1981 a 30/09/1991 e que possuíam sua área de drenagem completamente inserida em um mesmo sistema hidrogeológico. Neste período foram calculadas as vazões médias de cada estação e após este procedimento foram selecionados em cada estação três anos hidrológicos distintos que representassem os anos de vazões mínimas, os de vazões médias e os de vazões máximas.

Nos sistemas aluvional e carbonático não foram selecionadas estações fluviométricas, pois as estações que se encontram nesses sistemas possuem parte de sua área de drenagem em outros sistemas hidrogeológicos. 
Tabela 1 - Estações fluviométricas utilizadas

Table 1 - Fluviometric station used

\begin{tabular}{|c|c|c|c|c|c|c|}
\hline \multicolumn{3}{|c|}{ Estação fluviométrica } & \multirow{2}{*}{$\begin{array}{c}\text { Sistema } \\
\text { Aquífero }\end{array}$} & \multirow{2}{*}{ Rio } & \multirow{2}{*}{$\begin{array}{c}\text { Altitude } \\
(\mathrm{m})\end{array}$} & \multirow{2}{*}{$\begin{array}{c}\mathrm{AD} \\
\left(\mathrm{km}^{2}\right)\end{array}$} \\
\hline $\mathrm{N}^{\circ}$ & Nome & Código & & & & \\
\hline 1 & $\begin{array}{l}\text { Vargem } \\
\text { Bonita }\end{array}$ & 40025000 & Xistoso & $\begin{array}{c}\text { São } \\
\text { Francisco }\end{array}$ & 744 & 301 \\
\hline 2 & Rio Preto & 58550001 & Quartizítico & Rio Preto & 423 & 1804 \\
\hline 3 & $\begin{array}{l}\text { Tapiraí - } \\
\text { Jusante }\end{array}$ & 40060001 & $\begin{array}{l}\text { Pelítico- } \\
\text { Carbonático }\end{array}$ & $\begin{array}{l}\text { Rio da } \\
\text { Perdição }\end{array}$ & 623 & 569 \\
\hline 4 & Jequitibá & 41410000 & Pelítico & $\begin{array}{l}\text { Rio das } \\
\text { Velhas }\end{array}$ & 650 & 7080 \\
\hline 5 & Mucuri & 55520000 & $\begin{array}{l}\text { Gnassico- } \\
\text { Granítico }\end{array}$ & Mucuri & 336 & 2016 \\
\hline 6 & $\begin{array}{c}\text { Arinos } \\
\text { Montante }\end{array}$ & 43429998 & $\begin{array}{l}\text { Cobertura } \\
\text { Detrítica }\end{array}$ & Urucuia & 916 & 11800 \\
\hline 7 & $\begin{array}{l}\text { Iraí de } \\
\text { Minas }\end{array}$ & 60145000 & Basáltico & $\begin{array}{c}\text { Rio } \\
\text { Bagagem }\end{array}$ & 946 & 82 \\
\hline 8 & Veredas & 42840000 & Arenítico & $\begin{array}{l}\text { Rio San- } \\
\text { to Antô- } \\
\text { nio }\end{array}$ & 760 & 209 \\
\hline
\end{tabular}

AD: Área de Drenagem

Fonte: Brasil (2014) Source: Brasil (2014)

Na Tabela 2 são apresentadas as estações pluviométricas que foram utilizadas no trabalho e que estão localizadas nas proximidades das estações fluviométricas.

Tabela 2 - Estações pluviométricas utilizadas

Table 2 - Pluviometric stations used

\begin{tabular}{|c|c|c|c|c|}
\hline \multicolumn{3}{|c|}{ Estação Pluviométrica } & \multirow[b]{2}{*}{ Latitude } & \multirow[b]{2}{*}{ Longitude } \\
\hline Número & Nome & Código & & \\
\hline 1 & Vargem Bonita & 02046013 & $-20^{\circ} 19^{\prime} 48^{\prime \prime}$ & $-46^{\circ} 21^{\prime} 58^{\prime \prime}$ \\
\hline 2 & Fazenda São Gabriel & 02243202 & $-22^{\circ} 00^{\prime} 42^{\prime \prime}$ & $-43^{\circ} 52^{\prime} 30^{\prime \prime}$ \\
\hline 3 & Tapiraí - Jusante & 01946000 & $-19^{\circ} 52^{\prime} 46^{\prime \prime}$ & $-46^{\circ} 01^{\prime} 58^{\prime \prime}$ \\
\hline 4 & Fazenda Vargem Bonita & 01944024 & $-19^{\circ} 14^{\prime} 14^{\prime \prime}$ & $-44^{\circ} 07^{\prime} 23^{\prime \prime}$ \\
\hline 5 & Mucuri & 01741001 & $-17^{\circ} 35^{\prime} 42^{\prime \prime}$ & $-41^{\circ} 29^{\prime} 34^{\prime \prime}$ \\
\hline 6 & Arinos - Montante & 01546000 & $-15^{\circ} 55^{\prime} 28^{\prime \prime}$ & $-46^{\circ} 06^{\prime} 35^{\prime \prime}$ \\
\hline 7 & Iraí de Minas & 01847010 & $-18^{\circ} 58^{\prime} 55^{\prime \prime}$ & $-47^{\circ} 27^{\prime} 27^{\prime \prime}$ \\
\hline 8 & Canoeiros & 01845021 & $-18^{\circ} 20^{\prime} 18^{\prime \prime}$ & $-45^{\circ} 31^{\prime} 25^{\prime \prime}$ \\
\hline
\end{tabular}

Fonte: Brasil(2014) Source: Brasil (2014)

\subsection{Separação do escoamento}

A vazão em um curso d'água pode ser decomposta em escoamento superficial (ES) e escoamento de base (EB). Para obtenção do escoamento de base foi utilizado um filtro numérico com dois parâmetros (ECKHARDT, 2005; COLLISCHONN e FAN, 2013), conforme a equação 1:

$$
\mathrm{EB}_{\mathrm{i}=} \frac{\left(1-\mathrm{BFI}_{\max }\right) \cdot \mathrm{a} \cdot \mathrm{EB}_{\mathrm{i}-1}+(1-\mathrm{a}) \cdot \mathrm{BFI}_{\max } \cdot \mathrm{Q}_{\mathrm{i}}}{1-\mathrm{a} \cdot \mathrm{BFI}_{\max }}
$$

Em que: $\mathrm{EB}_{\mathrm{i}}$ é o escoamento de base em $\mathrm{m}^{3} \mathrm{~s}^{-1}$; i é o índice temporal; $\mathrm{Q}_{\mathrm{i}}$ é a vazão em $\mathrm{m}^{3} \mathrm{~s}^{-1}$; "a" é a constante de depleção do escoamento, adimensional e $\mathrm{BFI}_{\max }$ é a fração máxima que o escoamento de base pode representar em relação à vazão, decimal.

A solução da equação obedeceu ao método descrito em Eckhardt et al. (2002) e Eckhardt (2005). Existem diversos métodos empíricos e numéricos para estimar o EB, 
porém, uma vez que não é possível medir diretamente o EB, não é possível estimar diretamente a precisão destes métodos. No entanto, os métodos baseados em filtros numéricos digitais têm obtido bons resultados (ECKHARDT, 2008; GONZALES et al., 2009). Além disso, o uso de uma técnica numérica permite menor subjetividade nos cálculos em comparação às técnicas de separação manual, o que facilita a reprodutibilidade do trabalho (LUCAS, 2012).

\subsection{Análise estatística}

Para se promover uma comparação direta entre os diferentes sistemas aquíferos, foi realizada análise de variância, sendo con- siderada como fonte de variação a porcentagem do escoamento de base em relação ao escoamento total (\%EB), e como repetição os anos hidrológicos anteriormente descritos. Identificada a existência de diferenças estatísticas significativas pela análise de variância, procedeu-se a um teste de comparação de médias pela metodologia de Scott e Knott (1974) ao nível de 5\% de probabilidade.

\section{RESULTADOS E DISCUSSÃO}

Os valores de escoamento total (LET) e escoamento de base (LEB) representados sob a forma de lâmina são apresentados na Tabela 3.

Tabela 3 - Lâmina escoada total (LET) e lâmina de escoamento de base (LEB) em milímetros (mm) para os anos de vazão mínima, média e máxima

Table 3 - Total runoff depth (LET) and base flow depth (LEB) in millimeters (mm) for the years of minimum, average and maximum flow

\begin{tabular}{cccccccc}
\hline \multirow{2}{*}{ Estação } & \multirow{2}{*}{$\begin{array}{c}\text { Sistema } \\
\text { Aquífero }\end{array}$} & \multicolumn{2}{c}{$\begin{array}{c}\text { Ano } \\
\text { de mínima }\end{array}$} & \multicolumn{2}{c}{$\begin{array}{c}\text { Ano } \\
\text { de média }\end{array}$} & \multicolumn{2}{c}{$\begin{array}{c}\text { Ano } \\
\text { de máxima }\end{array}$} \\
\cline { 3 - 8 } & & LET & LEB & LET & LEB & LET & LEB \\
\hline Vargem Bonita & Xistoso & 644,8 & 412,5 & 962,7 & 599,2 & 1362 & 805 \\
Rio Preto & Quartizítico & 706,6 & 536 & 1076,5 & 862,5 & 1361 & 988,6 \\
& Pelítico & & & & & & \\
Tapiraí & - & 471,7 & 316,8 & 637,8 & 433,9 & 1018,4 & 756,3 \\
Jusante & $\begin{array}{c}- \\
\text { Carbonático }\end{array}$ & & & & & & \\
Jequitibá & Pelítico & 305 & 199,7 & 462,2 & 248,8 & 709,6 & 356,6 \\
Mucuri & $\begin{array}{c}\text { Gnáissico } \\
\text {-Granítico }\end{array}$ & 90,2 & 56,7 & 244,5 & 193,9 & 401,8 & 282,8 \\
Arinos Montante & $\begin{array}{c}\text { Cobertura } \\
\text { Detrítica }\end{array}$ & 320 & 162,6 & 658,6 & 331,6 & 1024,3 & 518,3 \\
Iraí de Minas & Basáltico & 455,6 & 317,4 & 715,9 & 406,4 & 1152 & 850,7 \\
Veredas & Arenítico & 351,8 & 300,5 & 559,6 & 331,5 & 822,3 & 369,4 \\
\hline
\end{tabular}

É possível verificar que houve grande variação dos valores, tanto em relação aos anos hidrológicos, quanto em relação aos sistemas aquíferos. A situação mais pronunciada ocorreu no sistema aquífero GnáissicoGranítico, estação fluviométrica do Rio $\mathrm{Mu}-$ curi, onde as lâminas escoadas foram substancialmente inferiores às dos demais sistemas aquíferos. Neste caso, a precipitação tem um papel importante para explicar o menor escoamento (LUCAS, 2012).

Com os dados de precipitação média anual para os anos nos quais foram observadas as vazões mínimas, médias e máximas (Tabela 4), pode-se constatar que os sistemas aquíferos que apresentaram os menores valores de lâmina escoada também apresentaram os menores valores de precipitação média anual. 
Tabela 4 - Dados de precipitação média anual para os anos de vazão mínima, média e máxima

Table 4 - Average rainfall data for the years of minimum, mean and maximum flow

\begin{tabular}{cccc}
\hline Sistema aquífero & Pmin $(\mathrm{mm})$ & Pmed $(\mathrm{mm})$ & Pmax $(\mathrm{mm})$ \\
\hline Xistoso & 1444,6 & 1943,9 & 1672,3 \\
Quartizítico & 1800,1 & 1961,8 & 1942,1 \\
Pelítico-Carbonático & 1728,1 & 1673,4 & 2115,6 \\
Pelítico & 1089,8 & 1085,2 & 1433,3 \\
Gnássico-Granítico & 755,2 & 1143,5 & 1269,4 \\
Cobertura Detrítica & 1104,3 & 1353,0 & 1384,1 \\
Basáltico & 1248,2 & 1271,3 & 1201,7 \\
Arenítico & 1123,8 & 1069,8 & 1241,5
\end{tabular}

Precipitação média anual para os anos de vazão mínima (Pmin), média (Pmed) e máxima (Pmax)

Uma análise interessante dos dados é a

3) pela precipitação média anual (P) (Tabela relação dos escoamentos superficial e base com a precipitação. A Tabela 5 apresenta os 4) para os respectivos anos de mínima, média resultados da divisão da LEB e LET (Tabela e máxima.

Tabela 5 - Relação entre os escoamentos superficial e base com a precipitação sobre cada sistema hidrogeológico e para os anos de vazões mínimas, médias e máximas

Table 5 - Precipitation and superficial and base flow relation in the hydrogeological systems for the years of minimum, mean and maximum flow

\begin{tabular}{lcccccc}
\hline \multicolumn{1}{c}{ Sistema aquífero } & $\begin{array}{c}\text { EB/ } \\
\text { Pmin }\end{array}$ & $\begin{array}{c}\text { EB/ } \\
\text { Pmed }\end{array}$ & $\begin{array}{c}\text { EB/ } \\
\text { Pmax }\end{array}$ & $\begin{array}{c}\text { LET/ } \\
\text { Pmin }\end{array}$ & $\begin{array}{c}\text { LET/ } \\
\text { Pmed }\end{array}$ & $\begin{array}{c}\text { LET/ } \\
\text { Pmax }\end{array}$ \\
\hline Xistoso & 0,29 & 0,31 & 0,48 & 0,45 & 0,50 & 0,81 \\
Quartizítico & 0,30 & 0,44 & 0,51 & 0,39 & 0,55 & 0,70 \\
Pelítico-Carbonático & 0,18 & 0,26 & 0,36 & 0,27 & 0,38 & 0,48 \\
Pelítico & 0,18 & 0,23 & 0,25 & 0,28 & 0,43 & 0,50 \\
Gnássico-Granítico & 0,08 & 0,17 & 0,22 & 0,12 & 0,21 & 0,32 \\
Cobertura Detrítica & 0,15 & 0,25 & 0,37 & 0,29 & 0,49 & 0,74 \\
Basáltico & 0,25 & 0,32 & 0,71 & 0,37 & 0,56 & 0,96 \\
Arenítico & 0,27 & 0,31 & 0,30 & 0,31 & 0,52 & 0,66 \\
\hline
\end{tabular}

De modo geral pode-se observar valores crescentes da relação $\mathrm{EB} / \mathrm{P}$ conforme aumentam a intensidade dos eventos de precipitação e vazão, ou seja, os valores de EB/Pmax apresentam valores maiores do que os coeficientes EB/Pmin e EB/Pmed. Apenas no sistema Arenítico o EB/Pmax foi menor que EB/Pmed. Este comportamento ocorre devido à maior lâmina total escoada em anos de vazão máxima, uma vez que o escoamento base é dado como uma fração do escoamento total (MIRANDA et al., 2014).

Para a relação entre escoamento total
(LET) e precipitação média anual (P) o mesmo padrão foi observado, os maiores valores foram para LET/Pmax, seguido por LET/Pmed e LET/Pmin. Ou seja, nos anos em que foram observadas as maiores vazões, uma fração maior da precipitação foi convertida em escoamento (GROPPO et al., 2005).

Já a relação entre escoamento de base e escoamento total (\%EB), para os anos de vazões mínimas, médias e máximas, bem como a médias destes valores, o coeficiente de variação $(\mathrm{CV})$ e o teste de comparação de médias estão apresentados na Tabela 6 . 
Tabela 6 - Relação entre escoamento de base e escoamento total para os anos de vazões mínimas, médias e máximas

Table 6 - Representation of the base flow on the total runoff for the years of minimum, mean and maximum flow

\begin{tabular}{|c|c|c|c|c|c|c|}
\hline \multirow[b]{2}{*}{ Estação } & \multirow[b]{2}{*}{$\begin{array}{l}\text { Sistema } \\
\text { Aquífero }\end{array}$} & \multicolumn{4}{|c|}{$\% \mathrm{~EB}$} & \multirow[b]{2}{*}{$\begin{array}{l}\text { CV } \\
(\%)\end{array}$} \\
\hline & & Mínima & Média & Máxima & $\begin{array}{l}\text { Média } \\
\text { geral }^{*}\end{array}$ & \\
\hline $\begin{array}{l}\text { Vargem } \\
\text { Bonita }\end{array}$ & Xistoso & 63,97 & 62,25 & 59,1 & $\begin{array}{c}61,80 \\
a \\
76,20\end{array}$ & 3,99 \\
\hline Rio Preto & Quartizítico & 75,85 & 80,13 & 72,64 & $\mathrm{~b}$ & 4,93 \\
\hline $\begin{array}{l}\text { Tapiraí } \\
\text { Jusante }\end{array}$ & $\begin{array}{c}\text { Pelítico- } \\
\text { Carbonático }\end{array}$ & 67,15 & 68,03 & 74,26 & $\begin{array}{c}69,80 \\
b\end{array}$ & 5,55 \\
\hline Jequitibá & Pelítico & 65,49 & 53,82 & 50,25 & $\begin{array}{c}56,50 \\
a\end{array}$ & 14,11 \\
\hline Mucuri & $\begin{array}{l}\text { Gnáissico } \\
\text {-Granítico }\end{array}$ & 62,90 & 79,30 & 70,39 & $\begin{array}{c}70,90 \\
\text { b }\end{array}$ & 11,58 \\
\hline $\begin{array}{c}\text { Arinos } \\
\text { Montante }\end{array}$ & Cobertura Detrítica & 50,82 & 50,35 & 50,60 & $\begin{array}{c}50,60 \\
a\end{array}$ & 0,46 \\
\hline $\begin{array}{l}\text { Iraí de } \\
\text { Minas }\end{array}$ & Basáltico & 69,68 & 56,77 & 73,85 & $\begin{array}{c}66,80 \\
b\end{array}$ & 13,33 \\
\hline \multirow[t]{2}{*}{ Veredas } & Arenítico & 85,43 & 59,24 & 44,92 & $\begin{array}{c}63,20 \\
\mathrm{~b}\end{array}$ & 32,50 \\
\hline & Média Geral & 67,66 & 63,74 & 62,00 & 64,50 & \\
\hline
\end{tabular}

*Letras iguais na média geral da \%EB significam que estatisticamente não se diferem os sistemas aquíferos.

Nota-se que não houve grandes variações na representatividade do escoamento de base em relação ao escoamento total entre os diferentes anos hidrológicos estudados, com exceção do sistema aquífero arenítico na estação Vereda que apresentou um coeficiente de variação da ordem 32,50\%.

A análise de variância entre os diferentes sistemas hidrogeológicos detectou diferenças estatisticamente significativas
(95\% de confiança) entre o comportamento dos sistemas aquíferos. Já com o teste de comparação de médias, verificou-se a semelhança de comportamento entre os sistemas hidrogeológicos xistoso, pelítico e cobertura detrítica, as quais apresentaram relação entre o escoamento de base e o escoamento total menores que para os demais sistemas aquíferos (Figura 2). 


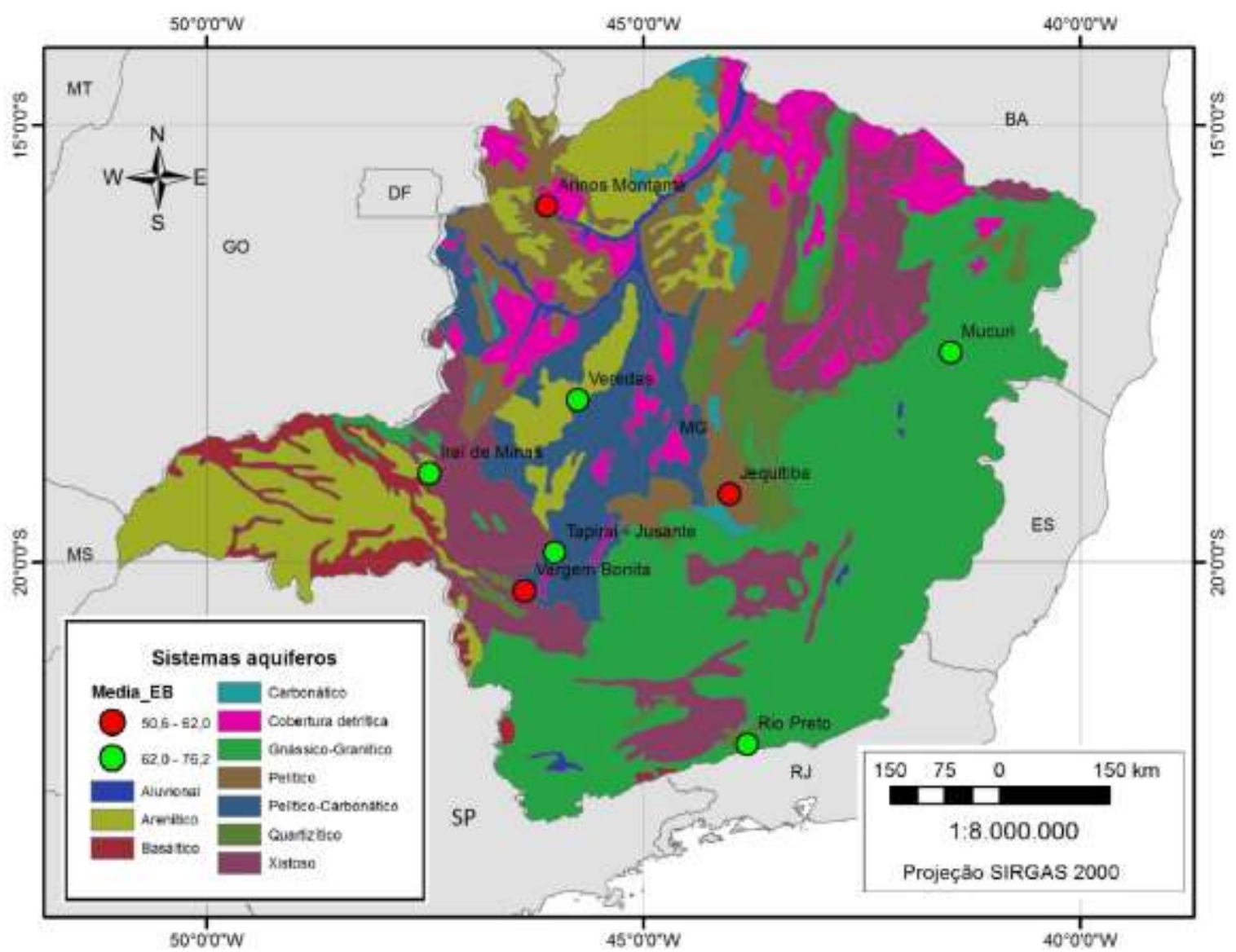

Figura 2 - Localização das estações fluviométricas com suas respectivas vazões de escoamento de base para ano de média, segundo os grupos estatísticos e os sistemas hidrogeológicos

Figure 2 - Fluviometric stations localization with their respective base flows for the average year, according to statistical groups and hydrogeological systems

As diferenças estatísticas encontradas não coincidem com as características hídricas esperadas dos sistemas aquíferos. As formações geológicas do grupo "a" (xistosas e pelíticas) referem-se a aquíferos fissurados, enquanto a cobertura detrítica corresponde a aquíferos granulares, entretanto essas três formações foram indicadas como estatisticamente equivalentes. Os demais foram incluídos na classe "b" pelo teste estatístico, mesmo com características hídricas bem distintas, fissurados, granulares e cársticofissurado.

Tal comportamento pode ser explicado ao se considerar que o efeito da geologia na relação entre escoamento de base e a vazão dos cursos d'água é indireto. A geologia determina os tipos de solos e a morfologia do terreno nas bacias hidrográficas; estes por sua vez determinam o regime de infiltração, percolação e escoamento da água na superfí- cie e no interior do solo (COSTA e BACELLAR, 2010). Assim, os resultados descrevem como a soma desses fatores determina a relação EB/ET, e não o sistema aquífero e o tipo de aquífero diretamente.

Trabalhos encontrados na literatura reforçam os efeitos indiretos que a geologia exerce sobre o comportamento do escoamento de base em relação ao escoamento total. Costa e Bacellar (2010) estudaram o comportamento desta relação em diversas microbacias sob diferentes domínios hidrogeológicos, e encontraram valores de \%EB maiores nas bacias com predomínio de xistos e filitos quando comparadas às de granito-gnaisse. Estes autores destacam que processos erosivos e a área de drenagem também influenciam na relação EB/ET.

Já as regiões com rocha arenítica têm um comportamento bem característico de elevada participação do escoamento de base 
na vazão dos cursos d'água (BARRETO et al., 2006; BARBOSA et al., 2014; GASPAR, 2006). Este comportamento é ainda mais destacado em regiões de clima semiárido, com valores de \%EB de até 95\% (ALBUQUERQUE e CHAVES, 2011).

Por outro lado, os aquíferos formados em rochas quartzíticas geralmente apresentam baixa \%EB, como na pequena bacia localizada no quadrilátero com $40 \%$ de EB/ET (BEATO et al., 2013). Entretanto, para a estação fluviométrica do Rio Preto, os valores encontrados no presente estudo foram sempre superiores a 70\%, o que indica elevada participação do EB na vazão do rio. Neste rio, há grande influência da geologia do embasamento cristalino, caracterizado nesta região pelo profundo manto de intemperismo com grande armazenamento de água e, por conseguinte, pelos elevados valores da razão EB/ET (PANE e PEREIRA, 2005).

A estação fluviométrica Mucuri, representativa para o sistema aquífero GnaisseGranítico do embasamento, apresenta elevado EB e \%EB (Tabela 5). Em concordância com estes resultados, Fernandes et al. (2010) obtiveram valores de \%EB de cerca de $62 \%$ para a bacia do Rio Sorocaba sobre litologia de Gnaisse e Granito.

É interessante perceber que os três sistemas aquíferos identificados com a letra "a" no teste de médias referem-se às bacias com domínio de solos rasos (cambissolos e neossolos), o que pode explicar a menor participação do escoamento de base na vazão

\section{REFERENCIAS}

ALBUQUERQUE, A. C. L. S.; CHAVES, H. M. L. Estimativa de recarga da bacia do Rio das Fêmeas através de métodos manuais e automáticos. Revista Brasileira de Engenharia Agrícola e Ambiental, v .15, p.1123-1129, 2011. Disponível em: <http://www.scielo.br/pdf/rbeaa/v15n11/03.pdf>. Acesso em: 28 jul. 2015.

BARBOSA, N. S.; LEAL, L.R.B. BARBOSA, N. S.; MELLO, J.C.; SANTOS, C.B.; LIMA, O.A.L. Caracterização geométrica e hidráulica do Sistema Aquífero Urucuia Meridional com base em testes de aquífero e levantamentos geofísicos. Águas Subterrâneas, v. 28, n. 2 p. 41-52, 2014. anual dos cursos d'água, já que o armazenamento e transmissão de água nesses solos é limitado. Desta maneira, a relação entre os sistemas aquíferos e as fases do escoamento é indireta pois a geologia é um dos fatores de formação do solo, este por sua vez tem relação com a cobertura vegetal que, em conjunto, determinam o comportamento hídrico nas bacias hidrográficas.

\section{CONCLUSÕES}

Embora as diferenças no escoamento de base (\%EB) não possam ser relacionadas diretamente às características dos aquíferos analisados, é possível observar que os sistemas hidrogeológicos exercem influência indireta na relação entre o escoamento de base e a vazão dos cursos d'água. Esta relação indireta foi evidenciada neste trabalho pela diferença estatisticamente significativa do escoamento base, sobretudo nos sistemas aquíferos com predomínio de solos rasos.

A relação dos escoamentos superficial e de base com a precipitação anual aumenta nos anos com maiores vazões nos cursos d'água, portanto uma maior parcela da precipitação se converte em vazão.

O escoamento de base representou, em todos os casos e para todos os sistemas aquíferos, mais da metade da vazão do curso d'água. Reforça-se assim a importância de se favorecer os processos de infiltração nas bacias hidrográficas.

BARRETO, C.E.A.G.; WENDLAND, E.; GOMES, L.H.; MARCUZZO, F.F.N. A interação rio-aquiífero na bacia do Ribeirão da Onça: aplicação de equações empíricas para estimativa do escoamento de base. In: Suplementos, XIV Congresso Brasileiro de Águas Subterrâneas. 2006. 20p. Disponível em: <http://aguassubterraneas.abas.org/asubterraneas/issue /view/1185/showToc>. Acesso 20/07/2015.

BEATO, D.A.C.; MONSORES, A.M.; BERTACHINI, A.C. Potencial aquífero nos metassedimentos do Quadrilátero Ferrífero - região da APA Sul RMBH MG. In: XIV Congresso Brasileiro de Geologia. Anais. Rio de Janeiro, RJ, 2013. 
BRASIL. Agência Nacional de Águas. Hidroweb. Sistema de informações hidrológicas. 2014. Disponível em: <http://hidroweb.ana.gov.br/>. Acesso em: 06/05/2014.

COLLISCHONN, W.; FAN, F.M. Defining parameters for Eckhardt's digital baseflow filter. Hydrological Processes, v.27, n.18, p.2614-2622, 2013.

COMBALICER, E.A.; LEE, S. H. AHN, S.; KIM, D. Y. IM, S. Comparing groundwater recharge and base flow in the Bukmoongol small-forested watershed, Korea. Journal Earth System Science, v.117, n.5, p.553-566, 2008.

COSTA, F. M.; BACELLAR, L. A. M. Caracterização hidrogeológica de aquíferos a partir do fluxo de base. Revista Brasileira de Recursos Hídricos, v.15, p.173-183, 2010.

ECKHARDT, K. How to construct recursive digital filters for base flow separation. Hydrological Processes, v.19, p.507-515, 2005.

ECKHARDT, K. A comparison of baseflow indices, which were calculated with seven different baseflow separation methods. Journal of Hydrology, v.352, n.1-2, p.168-173, 2008.

ECKHARDT, K.; HAVERKAMP, S.; FOHRER, N. FREDE, H-G. SWAT-G, a version of SWAT 9.2 modified for application to low mountain range catchments. Physical Chemistry of the Earth, v.27, p.641-644, 2002.

FAN, F. M.; MELLER, A.; COLLISCHONN, W. Incorporação de filtro numérico de separação de escoamento na assimilação de dados para previsão de vazões utilizando modelagem hidrológica. Revista Brasileira de Recursos Hídricos, v.20, p.472-483, 2015.

FERNANDES, A.M.; NOLASCO, M.B.; MORTATTI, J. Estimativa do escoamento superficial rápido e sua carga em suspensão com a aplicação do modelo de separação de hidrogramas com filtros numéricos: bacia do rio Sorocaba - SP. Geociências, v.29, p.49$57,2010$.

GASPAR, M. T. P. Sistema Aquífero Urucuia: Caracterização regional e proposta de gestão. Brasília: UnB, 2006. 157p. Tese Doutorado. Disponível em: $<$ http://repositorio.unb.br/handle/10482/6742>. Acesso em: 05/05/2015.

GONZALES, A. L.; NONNER, J.; HEIJKERS, J.; UHLENBROOK, S. Comparison of different base flow separation methods in a lowland catchment. Hydrology and Earth System Sciences, v.13, p.2055-2068, 2009.
GROPPO, J. D.; MORAES, J. M.; BEDUSCHI, C. E.; MARTINELLI, L. A. Análise de séries temporais de vazão e precipitação em algumas bacias do Estado de São Paulo com diferentes graus de intervenções antrópicas. Geociências, v.24, p.181-193, 2005.

LAROCQUE, M.; FORTIN, V.; PHARAND, M. C.; RIVARD, C. Groundwater contribution to riverflows - using hydrograph separation, hydrological and hydrogeological models in a Southern Quebec aquifer. Hydrology and Earth System Sciences Discussions, v.7, p.7809-7838, 2010.

LUCAS, M. C. Influência da precipitação e do uso do solo sobre a taxa de recarga em zona de afloramento do Sistema Aquífero Guarani. São Carlos: Escola de Engenharia de São Carlos, USP, 2012, 154p. Dissertação de Mestrado. Disponível em: <http://www.teses.usp.br/teses/disponiveis/18/18138/t de-31102012-092335/pt-br.php>. Acesso em: $10 / 08 / 2015$

MARCUZZO, F. F. N.; SIMON, F. W.; KIRCHHEIM, R. E. Relação da hidrogeologia e os indicadores regionais de vazão na sub-bacia da Lagoa dos Patos. In: XVIII Congresso Brasileiro De Águas Subterrâneas. Anais. Belo Horizonte, MG, 2014. Disponível em: $<$ http://aguassubterraneas.abas.org/asubterraneas/issue /archive>. Acesso em: 08/10/2015.

MATTIUZI, C. D. P.; KIRCHHMEIM, R. COLLISCHONN, W.; FAN, F. M. Estimativa de recarga a partir da separação de escoamento de base em duas sub-bacias da bacia hidrográfica do Rio Ibicuí/RS. In: XVIII Congresso Brasileiro De Águas Subterrâneas. Anais. Belo Horizonte, MG, 2014. Disponível em: $<$ http://aguassubterraneas.abas.org/asubterraneas/issue /archive>. Acesso em: 08/10/2015.

MIRANDA, A. C. R.; PRUSKI, F. F.; MARTINEZ, M. A.; CECON, P. R. Métodos de separação dos escoamentos superficial direto e subterrâneo: estudo de caso para a Bacia do Rio das Velhas. Revista Brasileira de Recursos Hídricos, v. 19, p.169-181, 2014.

PANE, E. PEREIRA, S.Y. As fontes em Itamonte, sul de Minas Gerais - uma contribuição para o entendimento das relações entre água superficial e subterrânea. Águas Subterrâneas, v.19, n.1, p.1-14, 2005.

PARTINGTON, D.; BRUNNER, P.; SIMMONS, C.T. Evaluation of outputs from automated baseflow separation methods against simulated baseflow from a physically based, surface water-groundwater flow model. Journal of Hydrology, v.458-459, p.28-39, 2012.

PINDER, G.F.; CELIA, M. A. Subsurface Hydrolo- 
gy.1.ed. Hoboken, NJ, USA: John Wiley \& Sons Inc., 2006. 468p.

PONTES, L.M. COELHO, G. MELLO, C.R. SILVA, A.M.; OLIVEIRA, G. C. Análise de sensibilidade e avaliação da estrutura do modelo BALSEQ em condições distintas de clima, solo e vegetação. Revista Brasileira de Recursos Hídricas, v.20, n.1, p. 46-54, 2015.

RIBEIRO, J. P. M.; VELASQUES, L. N. M.; CARVALHO FILHO, C. A. Análise da recarga e da conexão hidráulica no sistema granular-fissural no Campus Pampulha da UFMG, Belo Horizonte, MG. In: XVIII Congresso Brasileiro De Águas Subterrâneas. Anais. Belo Horizonte, MG, 2014. Disponível em: <http://aguassubterraneas.abas.org/asubterraneas/issue /archive>. Acesso em: 07/10/2015.

SCOTT, A.J.; KNOTT, M. Accouter analysis methods for grouping means in the analysis of variants. Biometrics, v.30, p.507-512, 1974.

SILVA GONZAGA, R.F.; BACELLAR, L. DE A.P.; FERNANDES, K.N. Estimativa de parâmetros de aquíferos através do coeficiente de recessão em áreas do embasamento cristalino de Minas Gerais. Revista Escola de Minas, v.63 n.3, p.465-471, 2010.
SOPHOCLEOUS, M. Interactions between groundwater and surface water: the state of the science. Hydrogeology Journal, v.10, n.1, p.52-67, 2002.

SOPHOCLEOUS, M. The science and practice of environmental flows and the role of hydrogeologists. Ground water, v.45, n.4, p.393-401, 2007.

SOPHOCLEOUS, M. Review: groundwater management practices, challenges, and innovations in the High Plains aquifer, USA - lessons and recommended actions. Hydrogeology Journal, v.18, p.559-575, 2010.

SOUZA, J.A.D.; RIBEIRO, M. M. R.; VIEIRA Z. M. C. L. Gestão das Águas Subterrâneas no Estado da Paraíba: Proposta de Modelos de Cobrança. Revista Brasileira de Recursos Hídricos, v.15, p.121-132, 2010.

SOUZA, S.M.T. Disponibilidades hídricas subterrâneas no Estado de Minas Gerais. Belo Horizonte: Hidrossistemas/COPASA, 1995. 525p. 